\title{
Short stature, brachydactyly, and Peters' anomaly (Peters'-plus syndrome): confirmation of autosomal recessive inheritance
}

\author{
José Carlos Cabral de Almeida, Dimas F Reis, Juan Llerena Jr, João Barbosa Neto, Ricardo Lopes
} Pontes, Sônia Middleton, Luis Fernando Telles

\begin{abstract}
Two sibs with a phenotype characterised by short stature, brachydactyly, and ocular anomalies (Peters' anomaly) are reported (Peters'-plus syndrome). The consanguinity is in agreement with the proposed autosomal recessive inheritance.
\end{abstract}

In 1988, Saal et $a l^{1}$ described two sisters with an autosomal recessive Robinow-like syndrome with anterior ocular chamber cleavage anomalies and Thompson and Winter ${ }^{2}$ reported a boy with sclerocornea and a similar phenotype. We report on a sister and brother with similar features and consanguineous parents; the consanguinity is in agreement with the proposed autosomal recessive inheritance.

Case reports (figs 1 and 2)

Patient 1 was referred to our genetic clinic because of ocular abnormalities and short limbs. She was born at

Centro de Genética Médica, Instituto Fernandes Figueira, Rio de Janeiro, Brazil.

J C Cabral de Almeida, D F Reis, J Llerena Jr, J B Neto, R L Pontes

Unidade de Citogenética Humana, Instituto de Biofisica CCFㅇ (UFRJ), Rio de Janeiro, Brazil.

J C Cabral de Almeida, D F Reis, J Llerena Jr

Disciplina de Genética e Evolução, Universidade do Rio de Janeiro, Brazil.

$S$ Middleton

Serviço de Oftalmologia, Hospital de Bonsucesso, Rio de Janeiro, Brazil.

L F Telles

Correspondence to Dr Cabral de Almeida, Unidade de Citogenética Humana, Instituto de Biofisica CCF 0 , CCS Bloco G, Cidade Universitária, 22941 Rio de Janeiro, Brazil.

Received for publication 18 June 1990.

Revised version accepted for publication 27 September 1990.

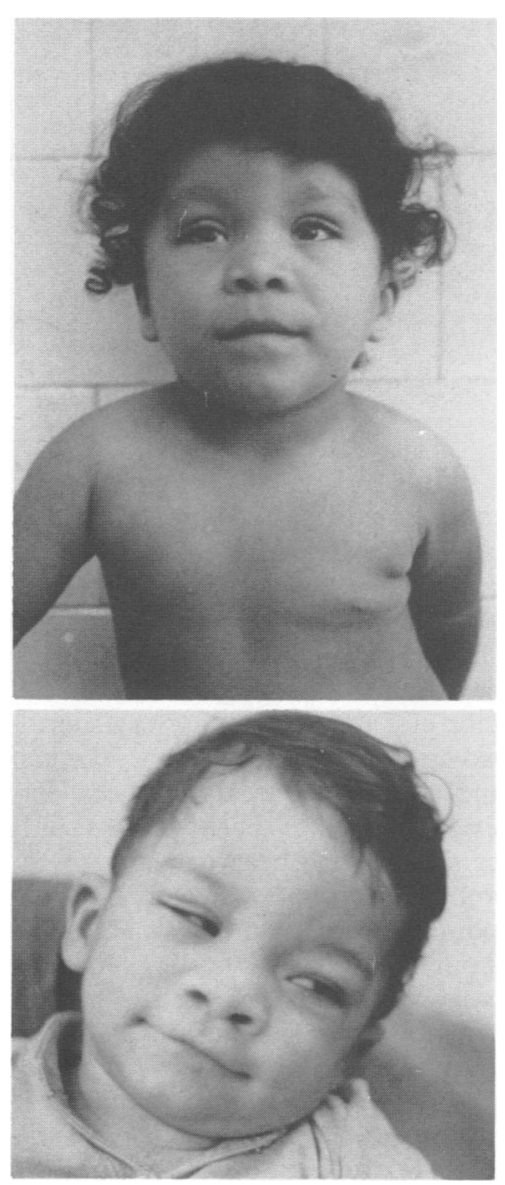

Figure 1 The affected sibs, aged 3 and 1 years.

term, weighing $2770 \mathrm{~g}$, with a height of $46 \mathrm{~cm}$, and a head circumference of $40 \mathrm{~cm}$. On physical examination, the proband showed prominent frontal bossing, ocular hypertelorism, bilateral corneal opacification, depressed nasal root, short nose with anteverted 


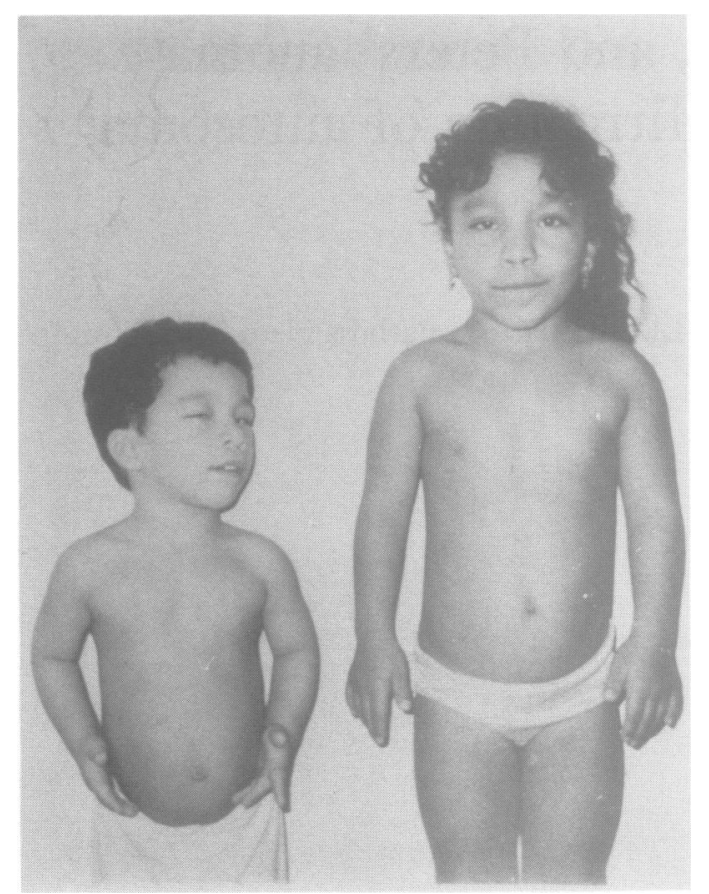

Figure 2 The sibs, aged 7 and 3 years.

nostrils and a broad tip, and thin lips with a cupid's bow mouth. She had widely spaced nipples with a symmetrical thoracic cage, and rhizomelic shortness of the limbs, more pronounced in the upper limbs. She also had short hands with brachydactyly and clinodactyly of both fifth fingers.

At the age of 7 the proband is very short $(103 \mathrm{~cm})$ with a head circumference of $53 \mathrm{~cm}$. The craniofacial and ocular abnormalities are unchanged. Her psychomotor development has been normal but a mild pulmonary stenosis had been detected.

The proband's parents are consanguineous (the great grandmothers are twin sisters) and they had had two children before the birth of the proband. The first pregnancy resulted in a boy who died just after birth and very much resembled the proband. The second pregnancy resulted in a normal girl. The parents asked for genetic counselling before their fourth pregnancy. Based on a diagnosis of Robinow-like syndrome in the proband, together with the obstetric history and the consanguineous marriage, a $25 \%$ risk was given, and prenatal diagnosis through a series of ultrasound scans was proposed to monitor future pregnancies. The parents returned a few years later with a 9 month old boy resembling his affected sister but presenting with more severe ocular abnormalities and limb shortness.

Patient 2 presented at 9 months; he was the youngest brother of patient 1 and was born at term weighing $3120 \mathrm{~g}$, height $46 \mathrm{~cm}$. He had ocular abnormalities and shortness of the limbs. On physical examination, there was a slightly prominent metopic suture, upward slanting palpebral fissures, epicanthus, bilateral leucoma with palpebral ptosis, left convergent strabismus and nystagmus, depressed and broad nasal root, macrostomia with thin lips, and a cupid's bow mouth. Rhizomelic and acromelic shortness of the limbs with brachydactyly and clinodactyly of both fifth fingers were present. At the age of 3 years (fig 2) he is intellectually normal and has the same facial features and rhizomelic shortness of the limbs (height $85 \mathrm{~cm}$ ) as his sister. He has a head circumference of $49.5 \mathrm{~cm}$. His ocular abnormalities are more severe, but no cardiovascular abnormalities were found.

\section{OPHTHALMOLOGICAL STUDIES}

Both sibs have a mesodermal dysgenesis with posterior embryotoxon, atrophy of the iridian stroma, microcornea, and corioectopia. The proband has evidence of bilateral corneal leucoma and her brother bilateral leucoma associated with bilateral cataract. The abnormalities found in both children are compatible with Peters' anomaly. The ocular abnormalities are more severe in the boy.

\section{OTHER STUDIES}

Radiological examination in both sibs showed ocular hypertelorism, brachydactyly of the hands and feet, and clinodactyly of the fifth fingers, but no other skeletal abnormalities except short limbs. Screening for inborn errors of metabolism, TORCH, and GTG karyotype analysis were normal.

\section{Discussion}

The similarity of the clinical picture of the sisters reported by Saal et $a l^{1}{ }^{1}$ the infant described by Thompson and Winter, ${ }^{2}$ and our cases is striking. Both these reports considered the possibility that the sibs investigated by Kivlin $e t a l^{3}$ may have had the same syndrome. Thompson and $\mathrm{W}^{2} \mathrm{~T}^{2}{ }^{2}$ also discussed the possibility that the patient described by Krause $e t a l^{4}$ may have been another example of the same clinical entity.

Van Schooneveld et $a l,{ }^{5}$ in 1984, described an autosomal recessive syndrome with short stature, brachydactyly, and Peters' anomaly which they termed 'Peters'-plus: a new syndrome'. The differences between this clinical picture and the one discussed here are, as pointed out by Thompson and Winter, ${ }^{2}$ the presence of cleft lip and palate in six patients, severe mental retardation in some, and abnormal ears. For these reasons the authors con- 
sidered Peters'-plus syndrome to be probably another clinical entity. However, the younger sister reported by Saal et al ${ }^{1}$ also had cleft lip and palate. Van Schooneveld $e t a f^{5}$ stated that the Peters'-plus syndrome could vary from a relatively mild condition to a very severe one, sometimes lethal in the fetus. Curiously, in our family, the first born child, apparently similarly affected, died soon after birth. We consider that these various reports probably represent the same clinical entity, characterised by short stature and rhizomelic brachydactyly associated with Peters' anomaly and other congenital and developmental abnormalities.

Fryns and Van den Berghe ${ }^{6}$ reported on a brother and sister with corneal clouding. Peters' anomaly, short arms and feet, growth retardation, low set ears, moderate to slight mental retardation, and subvalvular aortic stenosis in the girl. It is our impression that they may have had the same condition as the one described here and also reported by Saal $e t a^{1}$ and Thompson and Winter. ${ }^{2}$

The heterogeneity of Robinow syndrome has been recognised for some time. ${ }^{7}$ At least three types of syndrome presenting a 'Robinow phenotype' have been proposed: (1) Robinow syndrome with an autosomal dominant pattern of inheritance; (2) Robinow syndrome with an autosomal recessive pattern of inheritance. Both are clinically very similar; vertebral anomalies, found in $60 \%$ of the cases, ${ }^{8}$ are apparently more frequent and more severe in the autosomal recessive type. (3) 'Peters'-plus' syndrome with anterior ocular cleavage anomaly (Peters' anomaly). This form has an autosomal recessive pattern of inheritance and other abnormalities have been described, such as cleft lip/palate, early developmental delay, variable degrees of mental impairment, and, less frequently, cardiovascular anomalies. No vertebral anomalies have been reported so far. Cryptorchidism has been reported only once, but no genital hypoplasia has been described among eight male patients. The facial features are similar, but not identical, to Robinow syndrome. Early death has been identified in about $10 \%$ of cases with the diagnosis of Robinow syndrome; it seems that early mortality may be even more common in patients with Peters'-plus syndrome.

The authors are very grateful to Brazil Warrant, $\mathrm{CNPq}$, and Finep for financial support.

I Saal HM, Greenstein RM, Weinbaum PJ, Poole AE. Autosomal recessive Robinow-like syndrome with anterior chamber cleavage anomalies. Am f Med Genet 1988;30:709-18.

2 Thompson EM, Winter RM. A child with sclerocornea, short limbs, short stature, and distinct facial appearance. Am $\mathcal{F}$ Med Genet 1988;30:719-24.

3 Kivlin JD, Feireman RM, Crandall AS, Olson RJ. Peters' anomaly as a consequence of genetic and non-genetic syndromes. Arch Ophthalmol 1984;104:61-4.

4 Krause U, Koivisto M, Rantakallio P. A case of Peters' syndrome with spontaneous corneal perforation. $\mathcal{f}$ Pediatr Ophthalmol Strabismus 1969;6:145-9.

5 Van Schooneveld MJ, Dellerman JW, Beemer FA, BleeckerWagemakers EM. Peters'-plus: a new syndrome. Ophthalmic Paediatr Genet 1984;4:141-6.

6 Fryns JP, Van den Berghe H. Corneal clouding, subvalvular aortic stenosis and midface hypoplasia with mental retardation and growth retardation. I. Genetic causes of mental retardation. A personal contribution. Fryns FP. Thesis, Katholieke Universiteit, Leuven, 1986:377-81.

7 Smith D. In: Jones KL, ed. Recognizable patterns of human malformations. 4th ed. Philadelphia: Saunders. 1988.

8 Butler MG, Wadlington WB. Robinow syndrome: report of two patients and review of the literature. Clin Genet 1987;31:77-85. 